\title{
Trisomy 13 in monozygotic twins discordant for major congenital anomalies
}

\author{
N NAOR, Y AMIR, T COHEN*, AND S DAVIDSON \\ Department of Neonatology and *the Genetics Unit, Beilinson Medical Center and the Sackler School of \\ Medicine, Tel Aviv University, Israel.
}

SUMMARY The occurrence of trisomy 13 in twins is very rare. We report a pair of genotypically identical twins with trisomy 13 discordant for major anomalies. This case contributes to the already published data on the contribution of non-genetic factors to the aetiology of congenital malformations in monozygotic twins.

Bartolin in 1657 was the first to describe the pattern of anomalies which in 1960 was identified by Patau et $a l^{1}$ as being caused by the extra chromosome in the $\mathrm{D}$ (13 to 15$)$ group. Since then, numerous ${ }^{+}$ reports have been published focusing on the wide $e^{\infty}$ range of clinical features in this syndrome. ${ }^{2}{ }^{3} \mathrm{WeO}$ report the occurrence of trisomy 13 in twins whoo were identical genotypically and yet different ${ }^{-}$ phenotypically.

\section{Case report}

Male twins were spontaneously delivered at $32 \overrightarrow{0}$ weeks of gestation to a 38 year old gravida 8 mother. $v$ and a 45 year old father. Amniocentesis had been refused on religious grounds. No hereditary or

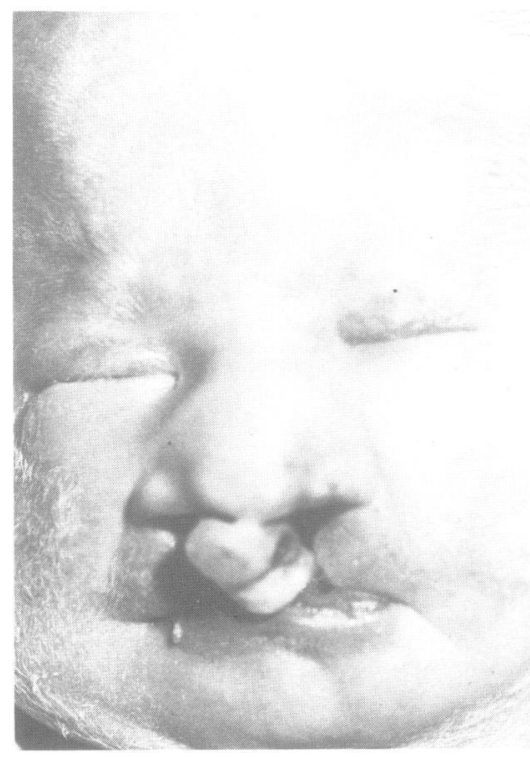

(a)

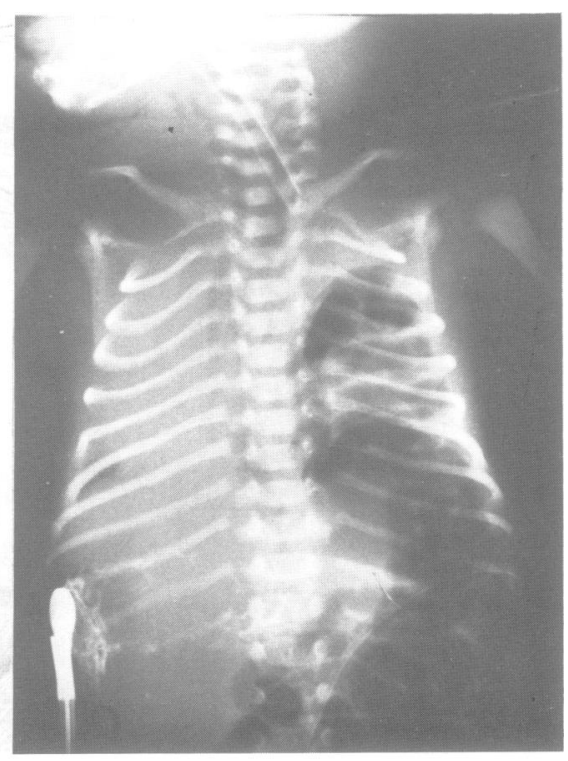

(b)

FIG 1 Major malformations in twin A: (a) bilateral cleft lip and palate, and (b) left diaphragmatic hernia. 
chromosomal disorders were noted in the family. Twin A, a breech presentation, was born with an Apgar score of 2 at one minute and weighed $1800 \mathrm{~g}$. Because of respiratory difficulty he was immediately intubated and ventilated. Twin B, a vertex presentation, had Apgar scores of 5 and 8 at one and five minutes and weighed $1850 \mathrm{~g}$. He was given oxygen and was intubated and ventilated at two hours of life for deteriorating respiratory distress. The initial physical examination of twin A showed trigonocephaly, dysplastic low set ears, microphthalmia, severe bilateral cleft lip and palate (fig 1a), postaxial polydactyly of the left hand, a simian line on the left hand, hyperconvex fingernails, syndactyly of the left second, and third toes, bilateral rockerbottom feet, and micropenis. Chest $x$ ray showed left diaphragmatic hernia (fig 1b) with the heart displaced to the right. Echocardiographic studies showed a structurally normal dextroposed heart. Twin B had dysplastic low set ears, microphthalmia, postaxial polydactyly of the left hand, a left simian line, hyperconvex fingernails, syndactyly of the left second and third toes, bilateral rockerbottom feet, and micropenis. Chest $x$ ray showed dextrocardia without situs inversus (fig 2). The diagnosis of isolated dextrocardia was confirmed by echocardiography.

Chromosome studies were performed on peripheral lymphocytes by a modification of the banding technique of Seabright ${ }^{4}$ and showed the nondisjunction type of trisomy 13 in both twins.

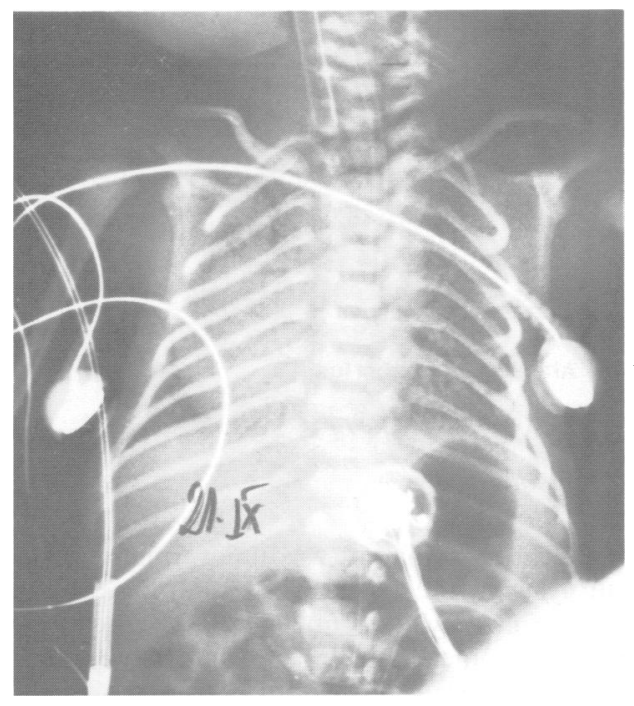

FIG 2 Major malformation in twin B: isolated dextrocardia.
Concordance was shown for both HLA antigens and blood groups $(\mathrm{O}+; \mathrm{C}+; \mathrm{E}-; \mathrm{c}-; \mathrm{N}+)$, establishing monozygosity. The condition of both twins rapidly deteriorated. Twin A died on the second day of life and twin B on the fifth day. Parental consent for necropsy was refused.

\section{Discussion}

It has been suggested that the incidence of congenital malformations in monozygotic twins is higher than in dizygotic twins and singleton infants. ${ }^{5-7}$ Although monozygotic twins share an identical hereditary genetic constitution, discordance with respect to congenital anomalies has been reported previously. ${ }^{5-7}$ The reported concordance rate of monozygotic twins for cleft lip or palate, central nervous system malformations, and congenital heart disease is only 10 to $40 \%$, suggesting a relatively low genetic contribution to the aetiology of these anomalies. ${ }^{8-10}$ The occurrence of Down's syndrome in twins has been extensively studied. The estimated concordance rate for trisomy 21 in monozygotic twins is 80 to $100 \% .{ }^{611}$ Although concordant for the genotype, a different phenotype (major congenital malformation in only one twin) has been previously reported, ${ }^{12}$ emphasising the role of non-genetic factors in the development of malformations.

To the best of our knowledge, this is the first published case of trisomy 13 in twins. Although in this case concordance was proven for the genotype, the twins differed markedly in their major congenital malformations. Twin A had severe cleft lip and palate, left diaphragmatic hernia, and trigonocephaly, while twin B had isolated dextrocardia without recognisable cardiac defects.

Two basic explanations for congenital malformations in twins exist: (1) the germ cell theory, which assumes the defect to be present in the gametes before fertilisation, and (2) the environmental theory, which assumes that the defect is produced after fertilisation has taken place. ${ }^{11}$ As this phenomenon in monozygotic twins cannot be explained on the basis of dissimilar genetic constitution, intrauterine environmental influences and the action of a variety of unknown exogenous agents must be considered as the possible mechanism for this condition. ${ }^{11} 13$

\footnotetext{
References

1 Patau K, Smith DW, Therman E, Inhorn SL, Wagner HP. Multiple congenital anomalies caused by an extra autosome. Lancet $1960 ; \mathbf{i}: 790-3$.

2 Conen PE. Phillips KG, Mauntner LS. Multiple developmental anomalies and trisomy of a 13-15 group chromosome (D syndrome). Can Med Assoc J 1962:87:709-12.
} 
${ }^{3}$ Warkany J, Passage E, Smith LB. Congenital malformations in autosomal trisomy syndromes. Am J Dis Child 1966;112:502-17.

${ }^{4}$ Seabright M. A rapid banding technique for human chromosomes. Lancet 1971;ii:971-2.

${ }^{5}$ Schinzel AAGL, Smith DW, Miller JR. Monozygotic twinning and structural defects. J Pediatr 1979;95:921-30.

${ }^{6}$ Hay S, Wehrung DA. Congenital malformations in twins. Am J Hum Genet 1970;22:662-78.

7 Fogel BJ, Nitowsky HM, Gruenwald P. Discordant abnormalities in monozygotic twins. J Pediatr 1965;66:64-72.

${ }^{8}$ Metrakos JD, Metrakos K. Baxter H. Clefts of the lips and palate in twins. Plast Reconstr Surg 1958;22:109-22.

9 Record RG, McKeown T. Congenital malformations of the central nervous system: data on sixty-nine pairs of twins. Ann Eugen 1951;15:285-92.
${ }^{10}$ Nora JJ, Gilliland JC, Sommerville RJ, McNamara DG. Congenital heart disease in twins. N Engl J Med 1967;277:56871.

1 Friedman A. Mongolism in twins. Am J Dis Child 1955;90:43 50 .

12 Young RJ. Mongolism in both of monozygotic twins. Arch Dis Child 1954;29:55-9.

13 Morison JE. Congenital malformations in one of monozygotic twins. Arch Dis Child 1949;24:214-8.

Correspondence and requests for reprints to $\operatorname{Dr} \mathrm{N}_{\vec{\omega}}$ Naor, Department of Neonatology, Beilinson Medical Center, 49100 Petah Tiqva, Israel.

\title{
Partial trisomy $17 \mathrm{q}$ and a generalised bone dysplasia in a 12 week fetus
}

\author{
ANNE ROBB*, LINDA FORSYTH†, AND JOHN TOLMIE \\ ${ }^{*}$ Department of Pathology, Raigmore Hospital, Inverness; + Cytogenetics Laboratory, The Royal Northern \\ Infirmary, Inverness; and $\ddagger$ Duncan Guthrie Institute of Medical Genetics, Yorkhill Hospitals, Glasgow.
}

SUMMARY A fetus, which was spontaneously aborted at 12 weeks' gestation, was found to have a generalised bone dysplasia and an unbalanced karyotype with trisomy for $17 \mathrm{q} 23 \cdot 1 \rightarrow$ qter due to a maternal translocation: $46, \mathrm{XX}, \mathrm{t}(5 ; 17)(\mathrm{p} 15 \cdot 3 ; \mathrm{q} 23 \cdot 1) \mathrm{mat}$.

We present the clinical details of a fetus, spontaneously aborted at 12 weeks' gestation, which had an unbalanced translocation between chromosomes 5 and 17 and a generalised bone dysplasia.

\section{Case report}

The fetus was the product of the third pregnancy of a non-consanguineous Scottish couple. The pedigree is shown in fig 1 . Their first pregnancy was terminated at 20 weeks' gestation when anencephaly was diagnosed in the fetus by ultrasound examination. The second pregnancy aborted spontaneously at eight weeks' gestation. No pathological or cytogenetic studies were performed on either abortus. Chromosome analysis was performed on both parents and the proband was found to be the carrier of a balanced reciprocal translocation, 46,XX, $\mathrm{t}(5 ; 17)(\mathrm{p} 15 \cdot 3 ; \mathrm{q} 23 \cdot 1)$ which she had inherited from her mother (fig 1). The present fetus aborted spontaneously at 12 weeks' gestation. Macroscopic examination revealed abnormally short limbs and a cleft palate and the phenotypic sex was male (fig 2).

Received for publication 29 January 1986.

Revised version accepted for publication 16 June 1986

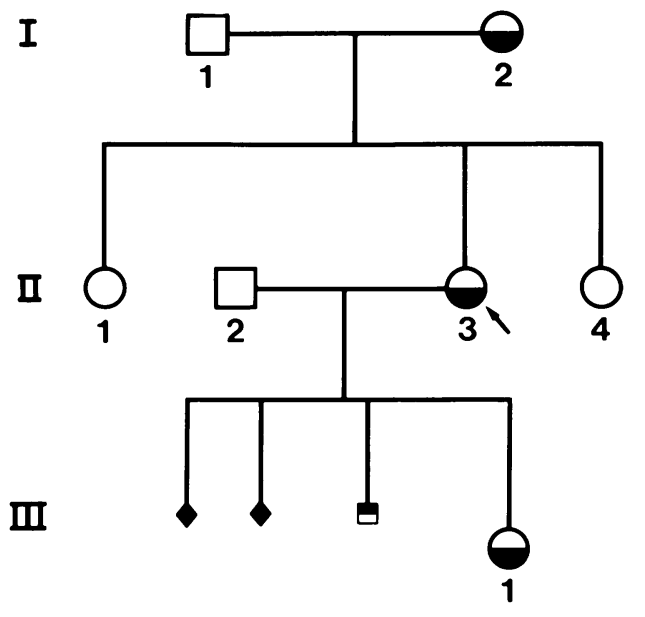

Translocation carrier

Affected male abortus

Normal karyotype

FIG 1 Family pedigree.

nistological examination was uninformative because

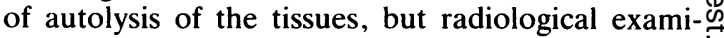
nation was grossly abnormal (fig 2). Ossification was 0 retarded in some bones but not in others and there $\overrightarrow{0}$ was undermineralisation of the cranial vault. The $\stackrel{\mathbb{\Omega}}{\mathbb{D}}$ clavicles were short and broad, the scapulae were $\mathbb{D}$ hypoplastic, and the ribs were short. The spine was 